\title{
Analytical solutions of polymer transport in porous media under magnetic effect
}

\author{
Mohamed F. El-Amin ${ }^{1,2, *}$ \\ ${ }^{1}$ Energy Research Laboratory, College of Engineering, Effat University, 21478 Jeddah, Kingdom of Saudi Arabia \\ ${ }^{2}$ Department of Mathematics, Faculty of Science, Aswan University, 81528 Aswan, Egypt
}

Received: 31 January 2020 / Accepted: 7 April 2020

\begin{abstract}
The analytical solution is helpful for understanding the mechanism and physical impacts and validating a numerical method through the model issue. This paper is devoted to developing analytical solutions for the problem of magnetic polymer transport in porous media. The mathematical model has been firstly developed then the analytical solutions have been obtained. The magnetization is treated as a nonlinear function of the magnetic field strength. The effects of the parameters of magnetic/polymer/rock on the polymer concentration, pressure and velocity have been investigated. It was found that the magnetization enhances velocity and concentration; and has a significant effect on concentration for high permeabilities. Also, it was found that for high permeabilities the advection dominates, but for lower permeabilities the diffusion dominates. As the adsorption rate increases the polymer solution concentration decreases.
\end{abstract}

\section{Introduction}

Polymers are widely used in many industrial applications, in particular in the chemical industry [1] due to their wide range of characteristics. For example, polymer flooding is considered one of the most effective methods of Enhanced Oil Recovery (EOR). When a polymer is injected with water into an oil reservoir the physical properties of fluids and rocks can be changed. For example, polymer injection reduces the water mobility and thereby improving the volumetric-sweeping effect and the local displacement of the water-flood [2-5]. In addition, the dissolved polymer molecules increase the brine's viscosity, which in turn increases the water-front saturation. Also, due to the large polymer molecules, the permeability can also be reduced. In order to enable polymer expected role to control the mobility ratio, the polymer is always used with another EOR method like Polymer-Alternating Gas (PAG) method, surfactant-polymer flooding, Alkali-SurfactantPolymer (ASP) flooding, etc. [6]. In the EOR polymersflood, the Hydrolyzed PolyAcrylaMide (HPAM) has been widely used. However, the produced-water control is one of the common difficulties of using the HPAM for EOR. This is because in re-injected water, the residual HPAM may increase oil content and viscosity.

On the other hand, the magnetic field can be used with polymers in some applications such as the magnetic nanoparticles implementation to eliminate pollutants from the

\footnotetext{
* Corresponding author: momousa@effatuniversity.edu.sa
}

produced water without chemicals [7-10]. Another example is the usage of magnetic resonance imaging and measurements to monitor oil displacement by water-flooding and polymer flooding [11]. Also, Ming et al. [12] presented a magnetic resonance investigation for low-salinity waterflooding for EOR. An experimental study was presented by Lyu et al. [13] to investigate the application of NMR to spontaneous imbibition recovery of tight sandstones. In order to mobile a magnetic ferrofluid through porous media, a strong external magnetic field may be used. For example, an electromagnetic source, can be used to enhance oil recovery by magnetic ferrofluids [14-18].

A number of publications could be found in using magnetic field with polymers [19], however, there are a very few research on finding analytical solutions of the polymers transport in porous media under the effect of magnetic field. For example, Ford Versypt et al. [20] have derived an analytical solution to a reaction-diffusion model for autocatalytic degradation and erosion in polymer microspheres. Also, Lyu et al. [21] have introduced an analytical solutions to the models of the surface and bulk erosion of solid polymers.

In the present paper, we developed analytical solutions for the model of transport of magnetic polymer solution in porous media under the effect of external magnetic field. The remaining sections of this paper are arranged as; in Section 2, we develop a mathematical model consists of a group of differential equations, algebraic constraints, and initial/boundary conditions. Then, in Section 3, we introduce an analytical solution of the governing equation. 


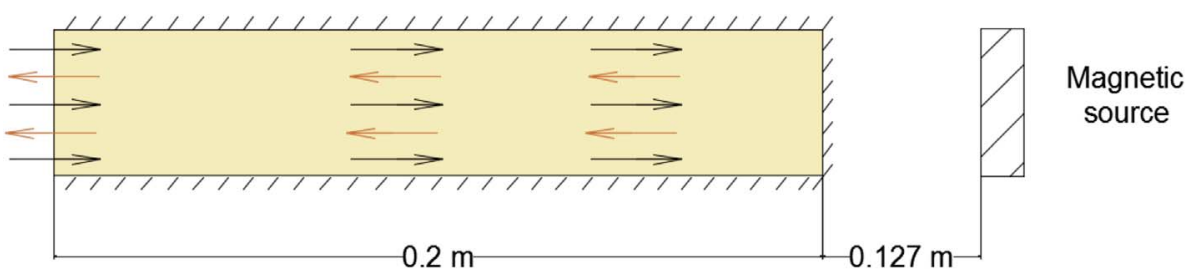

Fig. 1. Magnet is placed on the right side of the core, with a core length, $h=0.2 \mathrm{~m}$, and the magnet is positioned at $x=0.2 \mathrm{~m}$, $y=|x-0.2| \mathrm{m}$.

In Section 4, sensitivity analysis and physical discussion are presented. Finally, the conclusion is drawn in Section 5 .

\section{Modeling and formulation}

In this section, we develop the mathematical model of the problem of a single-phase flow with polymer-water flow under the effect of an external magnetic field (see Fig. 1). The polymer suspension gains properties from both liquid and magnetized solid particles. If the polymer suspension is subjected to an external magnetic field, it flows toward the magnetic field, and the flow resistance increases. In the absence of the magnet, nearby polymer acts as a normal liquid. In the following subsections, the model assumptions are stated, the mathematical models of polymer, flow, magnetic field, polymer viscosity, and initial/boundary conditions are sequentially presented.

\subsection{Assumptions}

The following assumptions are hold for the mathematical model. The flow is to be obeyed Darcy's law and the process is isothermal. The typical polymer size is smaller than the typical pore size. The fluid is compressible, and the rock is compressible and anisotropic. The viscosity of the polymer solution depends on the polymer concentration and the salinity coefficient. The mixture of water and polymer is assumed to be ideal (a homogeneous mixture of substances that has physical properties linearly related to the properties of the pure components). It is also assumed that the medium is free of polymer particles and a permanent magnet is the source of the magnetic field, we can use the simple equation to calculate the magnetic field strength directly. This assumption decouples the calculation of the external magnetic field from the polymer distribution. At a given location the gradient of the magnetic field strength can be calculated by a simple first-order differencing in each of the coordinate directions [22].

\subsection{Polymer model}

The balance equation of the polymer concentration is given by $[23,24]$,

$$
\begin{gathered}
\frac{\partial}{\partial t}\left(\frac{\phi(1-f) c}{B}\right)+\frac{\partial\left((1-\phi)(1-f) \rho_{r} c_{\mathrm{ad}}\right)}{\partial t} \\
+\frac{\partial}{\partial x} \frac{1}{\mathrm{BR}_{k}}\left(u c-\phi D \frac{\partial c}{\partial x}\right)=0
\end{gathered}
$$

such that,

$$
c_{\mathrm{ad}}=c_{\mathrm{ad}}(c)=c_{\mathrm{ad}, \max } \frac{\mathrm{d} c}{1+\mathrm{d} c},
$$

where $c\left[\mathrm{~m}^{3} \mathrm{~m}^{-3}\right]$ is the polymer concentration. $D\left[\mathrm{~m}^{2} \mathrm{~s}^{-1}\right]$ is the diffusion coefficient, $\rho_{r}\left[\mathrm{~kg} \mathrm{~m}^{3}\right]$ is the solid phase density, $R_{k}[-]$ is the permeability reduction factor, and $u\left[\mathrm{~m} \mathrm{~s}^{-1}\right]$ is velocity. $c_{\text {ad }}\left[\mathrm{m}^{3} \mathrm{~m}^{-3}\right]$ is the polymer adsorption concentration, $c_{\text {ad,max }}\left[\mathrm{m}^{3} \mathrm{~m}^{-3}\right]$ is the maximum polymer adsorption concentration, $d[-]$ is the adsorption coefficient. $\phi[-]$ is the porosity and $f[-]$ is the inaccessible pore volume factor. $B\left[\mathrm{~m}^{3} \mathrm{~m}^{-3}\right]$ is the formation volume factor. As the quantity $\mathrm{d} c$ can not equal -1 , the fraction $\frac{\mathrm{d} c}{1+\mathrm{d} c}$ in equation (2) may be expanded as,

$$
\frac{\mathrm{d} c}{1+\mathrm{d} c}=1-\frac{1}{1+\mathrm{d} c} \approx 1-\left(1-c d+(c d)^{2}+\cdots\right) \approx c d .
$$

The higher-order terms are ignored because $\mathrm{d} c<<1$. The permeability reduction factor is defined by,

$$
R_{k}=1+(\mathrm{RRF}-1) \frac{C_{\text {ad }}}{C_{\text {ad,max }}},
$$

where $\mathrm{RRF}$ is the ratio between the permeability before and after the polymer injection; RRF stands for the "Residual Resistance Factor". For seeking simplification, we consider $\mathrm{RRF}=1$, i.e. $R_{k}=1$, thus we ignore its effect on the transport equation. Therefore, the polymer transport equation (1) can be rewritten in the following form,

$$
R_{\phi} \frac{\partial c}{\partial t}+\frac{\mathrm{d}}{\mathrm{d} x}\left(u c-\phi D \frac{\partial c}{\partial x}\right)=0
$$

such that,

$$
R_{\phi}=(1-f)\left[\phi+(1-\phi) \rho_{r} \mathrm{~d} B c_{\mathrm{ad}, \max }\right] .
$$

\subsection{Flow model}

The external magnetic force acts as a body force of the momentum conservation equation, the 1D Darcy's equation is written as,

$$
u=-\frac{k}{\phi \mu_{e}}\left(\frac{\mathrm{d} p}{\mathrm{~d} x}+F_{\mathrm{mag}, x}\right) .
$$

The continuity equation is,

$$
\frac{\mathrm{d} u}{\mathrm{~d} x}=g(x),
$$


where $k\left[\mathrm{~m}^{2}\right]$ is the permeability, and $p[\mathrm{~Pa}]$ is the pressure. $\mu_{e}\left[\mathrm{~kg} \mathrm{~m}^{-1} \mathrm{~s}^{-1}\right]$ is the effective viscosity. In the absence of the magnetic field, $g(x)=0\left[\mathrm{~m}^{2} \mathrm{~s}^{-1}\right]$. Therefore, one obtains,

$$
\frac{\mathrm{d}}{\mathrm{d} x}\left[-\frac{k}{\phi \mu_{e}}\left(\frac{\mathrm{d} p}{\mathrm{~d} x}+F_{\text {mag }, x}\right)\right]=g(x) .
$$

Also, it is important to refer that $G(x)=\int_{0}^{x} g(x) \mathrm{d} x$ and $\left.G(x)\right|_{x=0}=u_{0}$.

\subsection{Magnetic field model}

Attractive forces can be produced on each particle of the suspension due to the interaction between the polarized nanoparticles with the external magnetic field. These external magnetic forces can be represented as body-forces on the suspension per unit volume [22], thus,

$$
\mathbf{F}_{\mathrm{mag}}=-\nabla\left[\mu_{0} \int_{0}^{H} v\left(\frac{\partial M}{\partial v}\right)_{H, T} \mathrm{~d} H\right]+\mu_{0} M \nabla H,
$$

where $H\left[\mathrm{~A} \mathrm{~m}^{-1}\right]$ is the magnetic field strength, $M\left[\mathrm{~A} \mathrm{~m}^{-1}\right]$ is the magnetization, and $\mu_{0}\left[\mathrm{~T} \mathrm{~m} \mathrm{~A}^{-1}\right]$ is the magnetic permeability. $v$ is the specific volume. Equation (8) can be rewritten as,

$$
\mathbf{F}_{\mathrm{mag}}=-\nabla\left[\mu_{0} \int_{0}^{H} v\left(\frac{\partial M}{\partial \rho}\right)_{H, T} \frac{\partial \rho}{\partial v} \mathrm{~d} H\right]+\mu_{0} M \nabla H .
$$

Because $v=\frac{1}{\rho}$, then, $\frac{\partial \rho}{\partial v}=-\frac{1}{v^{2}}$, the above equation can be written as,

$$
\mathbf{F}_{\text {mag }}=\nabla\left[\mu_{0} \int_{0}^{H} \frac{1}{v}\left(\frac{\partial M}{\partial \rho}\right)_{H, T} \mathrm{~d} H\right]+\mu_{0} M \nabla H .
$$

Thus,

$$
\mathbf{F}_{\mathrm{mag}}=\nabla\left[\mu_{0} \int_{0}^{H} \rho\left(\frac{\partial M}{\partial \rho}\right)_{H, T} \mathrm{~d} H\right]+\mu_{0} M \nabla H .
$$

The magnetization $M$ is a function of $H$, approximated by [14],

$$
M=a_{1} \tan ^{-1}\left(b_{1} H\right) .
$$

The range of $a_{1}\left[\mathrm{~A} \mathrm{~m}^{-1}\right]$ is of order $10^{2}-10^{5}$, and the order of $b_{1}\left[\mathrm{~m} \mathrm{~A}^{-1}\right]$ is of order $10^{-7}-10^{-3}$. The two parameters $a_{1}$ and $b_{1}$ depend on the ferromagnetic material type. Moreover, they can control the saturation magnetization and the initial susceptibility. In order to simplify equation (11), let us do the followings,

$$
\left(\frac{\partial M}{\partial \rho}\right)_{H, T}=\left(\frac{\partial M}{\partial a_{1}}\right)_{b_{1}, H, T}\left(\frac{\partial a_{1}}{\partial \rho}\right)+\left(\frac{\partial M}{\partial b_{1}}\right)_{a_{1}, H, T}\left(\frac{\partial b_{1}}{\partial \rho}\right) .
$$

From equation (12), one obtains,

$$
\left(\frac{\partial M}{\partial a_{1}}\right)_{b_{1}, H, T}=\tan ^{-1}\left(b_{1} H\right),
$$

and,

$$
\left(\frac{\partial M}{\partial b_{1}}\right)_{a_{1}, H, T}=a_{1} \frac{H}{1+b_{1}^{2} H^{2}} .
$$

The density of the magnetized fluid $\rho$ is assumed to be changed slightly from the non-magnetized density $\rho_{0}$. The partial derivatives, $\frac{\partial a_{1}}{\partial \rho}$ and $\frac{\partial b_{1}}{\partial \rho}$ are approximated around the points of non-magnetized case, i.e. $\left(a_{1,0}, b_{1,0}\right)=(0,0)$, thus,

$$
\begin{aligned}
& \frac{\partial a_{1}}{\partial \rho} \approx \frac{a_{1}-a_{1,0}}{\rho-\rho_{0}}=\frac{a_{1}}{\rho-\rho_{0}}, \\
& \frac{\partial b_{1}}{\partial \rho} \approx \frac{b_{1}-b_{1,0}}{\rho-\rho_{0}}=\frac{b_{1}}{\rho-\rho_{0}} .
\end{aligned}
$$

Thus,

$$
\begin{aligned}
\left(\frac{\partial M}{\partial \rho}\right)_{H, T} & =\tan ^{-1}\left(b_{1} H\right) \frac{a_{1}}{\rho-\rho_{0}}+a_{1} \frac{H}{1+b_{1}^{2} H^{2}} \frac{b_{1}}{\rho-\rho_{0}} \\
& =\frac{1}{\rho-\rho_{0}}\left(M+\frac{a_{1} b_{1} H}{1+b_{1}^{2} H^{2}}\right) .
\end{aligned}
$$

Therefore, equation (11) can be written as,

$$
\mathbf{F}_{\text {mag }}=\nabla\left[\mu_{0} \int_{0}^{H} \frac{\rho}{\rho-\rho_{0}}\left(M+\frac{a_{1} b_{1} H}{1+b_{1}^{2} H^{2}}\right) \mathrm{d} H\right]+\mu_{0} M \nabla H .
$$

Assuming that the variation in density is very small, therefore, the expression for the magnetic force may be rewritten as,

$$
\mathbf{F}_{\text {mag }}=\mu_{0} \frac{\rho}{\rho-\rho_{0}} \nabla\left[\int_{0}^{H}\left(M+\frac{a_{1} b_{1} H}{1+b_{1}^{2} H^{2}}\right) \mathrm{d} H\right]+\mu_{0} M \nabla H .
$$

Evaluating each integral term separately,

$$
\begin{aligned}
\int M \mathrm{~d} H & =\int a_{1} \tan ^{-1}\left(b_{1} H\right) \mathrm{d} H \\
& =H a_{1} \tan ^{-1}\left(b_{1} H\right)-a_{1} \log \frac{b_{1}^{2} H^{2}+1}{2 b_{1}} \\
& =M H-a_{1} \log \frac{b_{1}^{2} H^{2}+1}{2 b_{1}},
\end{aligned}
$$

and,

$$
\int \frac{a_{1} b_{1} H}{1+b_{1}^{2} H^{2}} \mathrm{~d} H=a_{1} \log \frac{b_{1}^{2} H^{2}+1}{2 b_{1}} .
$$

Then, sum the above two integrals to get,

$$
\int_{0}^{H}\left(M+\frac{a_{1} b_{1} H}{1+b_{1}^{2} H^{2}}\right) \mathrm{d} H=M H .
$$

Therefore,

$$
\mathbf{F}_{\text {mag }}=\mu_{0} \frac{\rho}{\rho-\rho_{0}} \nabla(M H)+\mu_{0} M \nabla H .
$$




\subsection{Polymer viscosity}

The polymer solution viscosity $\mu_{e}\left[\mathrm{~kg} \mathrm{~m}^{-1} \mathrm{~s}^{-1}\right]$ can be calculated by a third-order polynomial as described by the modified Flory-Huggins equation [25],

$$
\mu_{e}(c)=\mu_{w}\left[1+\left(A_{1} c+A_{2} c^{2}+A_{3} c^{3}\right) S_{p}\right],
$$

where $\mu_{w}\left[\mathrm{~kg} \mathrm{~m}^{-1} \mathrm{~s}^{-1}\right]$ is the viscosity of the aqueous phase (water), $c\left[\mathrm{~m}^{3} \mathrm{~m}^{-3}\right]$ is the polymer concentration and $S_{p}[-]$ is the salinity coefficient. The parameters, $A_{1}[-]$, $A_{2}[-]$ and $A_{3}[-]$ should be determined by experiments.

\subsection{Initial and boundary conditions}

The initial conditions are given as,

$$
c=0 \quad \text { at } \quad t=0, \quad 0 \leq x \leq h,
$$

where $h$ is the length. The boundary conditions are,

$$
\begin{array}{ccc}
u=u_{0}, & c=c_{0}, \quad \text { at } \quad t>0, \quad x=0, \\
p=p_{h}, & \frac{\mathrm{d} c}{\mathrm{~d} x}=0 \quad \text { at } \quad t>0, & x=h,
\end{array}
$$

such that $c_{0}\left[\mathrm{~m}^{3} \mathrm{~m}^{-3}\right]$ is the polymer concentration on the inlet. Thus, the specified constant concentration at the left boundary is given. When the source is located on the boundary $\left(\frac{\mathrm{d} c}{\mathrm{~d} x}=0\right)$ is somewhat misleading, because the symmetry of the Gaussian curve about its center allows $\left(\frac{d}{d x}=0\right)$ to be satisfied even as mass leaves the real domain. Analytical solutions that satisfy the no-flux boundary condition are found using the principle of superposition.

\section{Analytical solution}

The 1D $x$-component of $\mathbf{F}_{\text {mag }}[\mathrm{N}]$, equation (15), can be written as,

$$
\mathbf{F}_{\mathrm{mag}, x}=\left[\mu_{0} \frac{\rho}{\rho-\rho_{0}}\left(M+H \frac{\partial M}{\partial H}\right)+\mu_{0} M\right] \frac{\mathrm{d} H}{\mathrm{~d} x},
$$

or,

$$
\mathbf{F}_{\mathrm{mag}, x}=F(H) \frac{\mathrm{d} H}{\mathrm{~d} x},
$$

such that $F(H)$ is a nonlinear function of $H\left[\mathrm{~A} \mathrm{~m}^{-1}\right]$ defined as,

$$
F(H)=\mu_{0} \frac{\rho}{\rho-\rho_{0}}\left(M+H \frac{\partial M}{\partial H}\right)+\mu_{0} M .
$$

The term $\frac{\partial M}{\partial H}$ represents the magnetic susceptibility which is the substance magnetic response to the magnetic field.

Now, let us write the momentum equation, equation (7), in $1 \mathrm{D}$ form as,

$$
\frac{\mathrm{d} u}{\mathrm{~d} x}=\frac{\mathrm{d}}{\mathrm{d} x}\left[-\frac{k}{\phi \mu_{e}}\left(\frac{\mathrm{d} p}{\mathrm{~d} x}+F(H) \frac{\mathrm{d} H}{\mathrm{~d} x}\right)\right]=g(x) .
$$

Integrating equation (21) over $x$ and using the boundary condition $\left(u=u_{0}\right.$ at $\left.x=0\right)$, one obtains,

$$
-\frac{k}{\phi \mu_{e}}\left(\frac{\mathrm{d} p}{\mathrm{~d} x}+F(H) \frac{\mathrm{d} H}{\mathrm{~d} x}\right)=G(x) .
$$

Therefore,

$$
\frac{\mathrm{d} p}{\mathrm{~d} x}=-F(H) \frac{\mathrm{d} H}{\mathrm{~d} x}-\frac{u_{0} \phi \mu_{e}}{k} .
$$

Then integrate once more,

$$
p=-\int F(H) \mathrm{d} H-\frac{u_{0} \phi}{k} \int \mu_{e}(c) \mathrm{d} x+\text { const. }
$$

Now, let us calculate the first term,

$$
\int F(H) \mathrm{d} H=\mu_{0} \frac{\rho}{\rho-\rho_{0}} \int\left(M+H \frac{\partial M}{\partial H}\right) \mathrm{d} H+\mu_{0} \int M \mathrm{~d} H .
$$

It is easy to find,

$$
\int\left(M+H \frac{\partial M}{\partial H}\right) \mathrm{d} H=M H
$$

and,

$$
\int M \mathrm{~d} H=M H-\frac{a_{1}}{2 b_{1}} \ln \left(b_{1}^{2} H^{2}+1\right) .
$$

Therefore,

$\int F(H) \mathrm{d} H=\mu_{0} \frac{\rho}{\rho-\rho_{0}} M H+\mu_{0} M H-\mu_{0} \frac{a_{1}}{2 b_{1}} \ln \left(b_{1}^{2} H^{2}+1\right)$.

In order to estimate the integration $\int_{0}^{x} \mu_{e}(c) \mathrm{d} x$ in a simple way, we assume that concentration in the flow equation is mainly driven by advection and diffusion effect is ignored thus,

$$
R_{\phi} \frac{\partial c}{\partial t}+u \frac{\partial c}{\partial x}=0 .
$$

This is a linear advection equation has the following solution,

$$
c=c_{i}\left(x-\frac{u}{R_{\phi}} t\right)
$$

with the initial condition $c_{i}$. Also, we approximate the viscosity,

$$
\mu_{e}(c)=\mu_{w}\left(1+A_{1} S_{p} c\right) .
$$

Therefore,

$$
\int_{0}^{x} \mu_{e}(c) \mathrm{d} x=\mu_{w}\left(x+A_{1} S_{p} \int_{0}^{x} c \mathrm{~d} x\right)
$$

such that,

$$
\int_{0}^{x} c \mathrm{~d} x=c_{i}\left(\frac{x^{2}}{2}-\frac{t}{R_{\phi}} \int_{0}^{x} u \mathrm{~d} x\right)=c_{i}\left(\frac{x^{2}}{2}-\frac{t}{R_{\phi}} x\right) .
$$


Finally, one can write,

$$
\int_{0}^{x} \mu_{e}(c) \mathrm{d} x=\mu_{w}\left(x+A_{1} S_{p} c_{i}\left(\frac{x^{2}}{2}-\frac{t}{R_{\phi}} x\right)\right) .
$$

But in the current case of study the initial concentration of the polymer is zero, i.e. $c_{i}=0$. Therefore,

$$
\int_{0}^{x} \mu_{e}(c) \mathrm{d} x=\mu_{w} x
$$

Substituting the above terms in equations (26) and (33) into equation (24), one obtains,

$$
\begin{aligned}
p= & -\left[\mu_{0}\left(\frac{\rho}{\rho-\rho_{0}}+1\right) M H-\mu_{0} \frac{a_{1}}{2 b_{1}} \ln \left(b_{1}^{2} H^{2}+1\right)\right] \\
& -\frac{u_{0} \phi}{k} \mu_{w} x+\text { const. }
\end{aligned}
$$

Thus,

$$
\begin{gathered}
p=-\mu_{0} \frac{2 \rho-\rho_{0}}{\rho-\rho_{0}} M H+\mu_{0} \frac{a_{1}}{2 b_{1}} \ln \left(b_{1}^{2} H^{2}+1\right) \\
-\frac{u_{0} \phi}{k} \mu_{w} x+\text { const. }
\end{gathered}
$$

In order to determine the integration constant we use the boundary condition, $p=p_{h}$ at $x=h$. Therefore,

$$
\begin{aligned}
\text { const. }= & p_{h}+\mu_{0} \frac{2 \rho-\rho_{0}}{\rho-\rho_{0}}(M H)_{x=h}-\mu_{0} \frac{a_{1}}{2 b_{1}} \ln \left(b_{1}^{2} H_{x=h}^{2}+1\right) \\
& +\frac{u_{0} \phi}{k} \mu_{w} h .
\end{aligned}
$$

Thus,

$$
\begin{aligned}
p= & p_{h}+\mu_{0} \frac{2 \rho-\rho_{0}}{\rho-\rho_{0}}\left((M H)_{x=h}-M H\right)+\mu_{0} \frac{a_{1}}{2 b_{1}} \\
& \times \ln \frac{b_{1}^{2} H^{2}+1}{b_{1}^{2} H_{x=h}^{2}+1}+\frac{u_{0} \phi}{k} \mu_{w}(h-x) .
\end{aligned}
$$

Here, we calculate the pressure derivative which will be used in the velocity calculations. We used equation (12) for the definition of $M(H)=a_{1} \tan ^{-1} b_{1} H$,

$$
\begin{aligned}
\frac{\mathrm{d} p}{\mathrm{~d} x}= & -\mu_{0} \frac{2 \rho-\rho_{0}}{\rho-\rho_{0}}\left(\frac{b_{1} a_{1} H}{b_{1}^{2} H^{2}+1}+M\right) \frac{\mathrm{d} H}{\mathrm{~d} x}+\frac{\mu_{0} a_{1} b_{1} H}{b_{1}^{2} H^{2}+1} \\
& \times \frac{\mathrm{d} H}{\mathrm{~d} x}-\frac{u_{0} \phi \mu_{w}}{k} .
\end{aligned}
$$

The velocity is calculated with the aid of equations (21), (29) and (35) as,

$$
\begin{gathered}
u=-\frac{k}{\phi \mu_{w}\left(1+A_{1} S_{p} c\right)}\left(-\mu_{0} \frac{2 \rho-\rho_{0}}{\rho-\rho_{0}}\left(\frac{b_{1} a_{1} H}{b_{1}^{2} H^{2}+1}+M\right) \frac{\mathrm{d} H}{\mathrm{~d} x}\right. \\
\left.+\frac{\mu_{0} a_{1} b_{1} H}{b_{1}^{2} H^{2}+1} \frac{\mathrm{d} H}{\mathrm{~d} x}-\frac{u_{0} \phi \mu_{w}}{k}\right)
\end{gathered}
$$

The magnetic field strength in 1D may be written as follows [14],

$$
\begin{gathered}
H_{x}=\frac{B_{r}}{\pi \mu_{0}}\left(\tan ^{-1} \frac{a b}{x\left(a^{2}+b^{2}+x^{2}\right)^{1 / 2}}\right. \\
\left.-\tan ^{-1} \frac{a b}{(x+L)\left(a^{2}+b^{2}+(x+L)^{2}\right)^{1 / 2}}\right),
\end{gathered}
$$

where $L[\mathrm{~m}]$ is the distance between the poles of the magnet, and $B_{r}=1.19[\mathrm{~T}]$ is the residual magnetization. Therefore,

\section{See Equation bottom of the page}

Now, we present the solution of the concentration equation. Invoking the continuity equation in equation (4), we find,

$$
R_{\phi} \frac{\partial c}{\partial t}+u \frac{\partial c}{\partial x}=\phi D \frac{\partial^{2} c}{\partial x^{2}} .
$$

Using Laplace transforms and similar to reference [26], the solution of the above equation has been obtained as,

$$
\begin{aligned}
c=c_{i} & +\frac{c_{0}-c_{i}}{2}\left[\operatorname{erfc}\left(\frac{R_{\phi} x-u t}{2 \sqrt{\phi D R_{\phi} t}}\right)\right. \\
& \left.+\exp \left(\frac{u x}{\phi D}\right) \operatorname{erfc}\left(\frac{R_{\phi} x+u t}{2 \sqrt{\phi D R_{\phi} t}}\right)\right],
\end{aligned}
$$

such that,

$$
\begin{gathered}
\operatorname{erfc}(z)=1-\frac{1}{\sqrt{\pi}} \int_{-z}^{z} e^{-y^{2}} \mathrm{~d} y \\
=1-\frac{2}{\sqrt{\pi}} \int_{0}^{z} e^{-y^{2}} \mathrm{~d} y .
\end{gathered}
$$

Again, as the initial concentration of the polymer is zero, i.e. $c_{i}=0$, we have,

$$
c=\frac{c_{0}}{2}\left[\operatorname{erfc}\left(\frac{R_{\phi} x-u t}{2 \sqrt{\phi D R_{\phi} t}}\right)+\exp \left(\frac{u x}{\phi D}\right) \operatorname{erfc}\left(\frac{R_{\phi} x+u t}{2 \sqrt{\phi D R_{\phi} t}}\right)\right] .
$$

$$
\frac{\mathrm{d} H}{\mathrm{~d} x}=\frac{B_{r}}{\pi \mu_{0}}\left(\frac{-\frac{a b}{\sqrt{x^{2}+b^{2}+a^{2}}}-\frac{a b x^{2}}{\left(x^{2}+b^{2}+a^{2}\right)^{\frac{3}{2}}}}{\frac{a^{2} b^{2}}{\left(x^{2}+b^{2}+a^{2}\right)}+x^{2}}-\frac{-\frac{a b}{(x+L)^{2} \sqrt{(x+L)^{2}+b^{2}+a^{2}}}-\frac{a b}{\left((x+L)^{2}+b^{2}+a^{2}\right)^{\frac{3}{2}}}}{\frac{a^{2} b^{2}}{(x+L)^{2}\left((x+L)^{2}+b^{2}+a^{2}\right)}+1}\right) .
$$


From the definition of the complementary error function $\operatorname{erfc}(y)$, one can write,

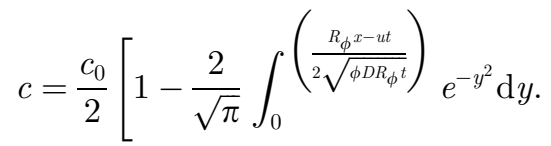

$$
\begin{aligned}
& \left.+e^{-\frac{u x}{\phi D}}\left(1-\frac{2}{\sqrt{\pi}} \int_{0}^{\left(\frac{R_{\phi^{x}}+u t}{2 \sqrt{\phi D R_{\phi}}}\right)} e^{-y^{2}} \mathrm{~d} y\right)\right] .
\end{aligned}
$$

In the case of advection absence, i.e., the above function will be reduced to the following simpler form,

$$
c=c_{0} \operatorname{erfc}\left(\frac{\sqrt{R_{\phi}} x}{2 \sqrt{\phi D t}}\right)
$$

or,

$$
c=c_{0}\left(1-\frac{2}{\sqrt{\pi}} \int_{0}^{\left(\frac{\sqrt{R_{\phi}} x}{2 \sqrt{\phi D t}}\right)} e^{-y^{2}} \mathrm{~d} y\right) .
$$

\section{Model validation}

In order to validate solutions, they should be compared to a given known solution. However, as there are no published solutions for the current model, we can compare the reduced model of some simple cases.

\subsection{Flow model validation}

In the case of magnetic field absence, the pressure equation (35) reduces into the linear form,

$$
p=p_{h}+\frac{u_{0} \phi}{k} \mu_{w}(h-x),
$$

which is the solution of the original pressure equation,

$$
\frac{\mathrm{d}}{\mathrm{d} x}\left[-\frac{k}{\phi \mu_{w}}\left(\frac{\mathrm{d} p}{\mathrm{~d} x}\right)\right]=g(x),
$$

which is coupling of momentum equation and the original Darcy's law, i.e.,

$$
\begin{gathered}
\frac{\mathrm{d} u}{\mathrm{~d} x}=g(x), \\
u=-\frac{k}{\phi \mu_{w}} \frac{\mathrm{d} p}{\mathrm{~d} x} .
\end{gathered}
$$

One can easily integrate equation (48) to obtain the linear pressure formulation (47). Also, the viscosity is treated as a constant.

\subsection{Polymer model validation}

Similar to the flow model reduction in the previous subsection, we do the same thing here. Recall the concentration equation (39), for a simple solute not a polymer $\left(R_{\phi}=\phi\right.$, $u=\hat{u} \phi)$, it may take the form [26],

$$
\frac{\partial c}{\partial t}+\hat{u} \frac{\partial c}{\partial x}=D \frac{\partial^{2} c}{\partial x^{2}} .
$$

This is the traditional advection-diffusion equation with the well-known solution [26],

$$
c=c_{i}+\frac{c_{0}-c_{i}}{2}\left[\operatorname{erfc}\left(\frac{x-\hat{u} t}{2 \sqrt{D t}}\right)+\exp \left(\frac{\hat{u} x}{D}\right) \operatorname{erfc}\left(\frac{x+u t}{2 \sqrt{D t}}\right)\right] .
$$

If the initial concentration is zero, i.e. $c_{i}=0$, we have,

$$
c=\frac{c_{0}}{2}\left[\operatorname{erfc}\left(\frac{x-\hat{u} t}{2 \sqrt{D t}}\right)+\exp \left(\frac{\hat{u} x}{D}\right) \operatorname{erfc}\left(\frac{x+u t}{2 \sqrt{D t}}\right)\right]
$$

or if one substitutes the error functions, gets,

$c=\frac{c_{0}}{2}\left[1-\frac{2}{\sqrt{\pi}} \int_{0}^{\left(\frac{x-\hat{x} t}{2 \sqrt{D t}}\right)} e^{-y^{2}} \mathrm{~d} y+e^{-\frac{i x t}{D}}\left(1-\frac{2}{\sqrt{\pi}} \int_{0}^{\left(\frac{x+\hat{u} t}{2 \sqrt{D t}}\right)} e^{-y^{2}} \mathrm{~d} y\right)\right]$.

For the pure diffusion $(\hat{u}=0)$ this formula reduces to,

$$
c=c_{0} \operatorname{erfc}\left(\frac{x}{2 \sqrt{D t}}\right)
$$

or,

$$
c=c_{0}\left(1-\frac{2}{\sqrt{\pi}} \int_{0}^{\left(\frac{x}{2 \sqrt{D t}}\right)} e^{-y^{2}} \mathrm{~d} y\right) .
$$

All the above concentration formula are well known solution for the concentration equations can be found in any common book such as [26].

\section{Results and sensitivity analysis}

In this section, we present a sensitivity analysis of the model parameters to study how they affect the results. In order to do this kind of analysis, the main dependent physical variables, $p, u$ and $c$ are examined against the physical primary parameters, $a_{1}, b_{1}, B_{r}, k, D, f$ and $d$. Figure 2 illustrates the effects of the magnetic parameter $a_{1}$ and permeability on the velocity profiles along the core length at $t=25[-], B_{r}=1.19$ $[\mathrm{T}], \quad a=b=0.0254[\mathrm{~m}], \quad L=0.127[\mathrm{~m}], k=1,5,10,50$ [md], $\mu_{0}=4 \times 10^{-7}\left[\mathrm{~T} \mathrm{~m} \mathrm{~A}^{-1}\right], \quad b_{1}=3 \times 10^{-7}\left[\mathrm{~m} \mathrm{~A}^{-1}\right]$, $p_{0}=1 \times 10^{6}[\mathrm{~Pa}], u_{0}=5 \times 10^{-5}\left[\mathrm{~m} \mathrm{~s}^{-1}\right], \phi=0.3[-]$, $\mu=0.001\left[\mathrm{~kg} \mathrm{~m}^{-1} \mathrm{~s}^{-1}\right]$. The unit "md" is a popular permeability unit called millidarcy such that 1 [md] = $0.9869 \times 10^{-15}\left[\mathrm{~m}^{2}\right]$. One can observe from this figure that as the magnetization increases (by increasing $a_{1}$ ) the velocity increases. Also, it has a clear effect on the velocity such that as the permeability increases the velocity increases which obeys Darcy's law. The effects of the magnetic 

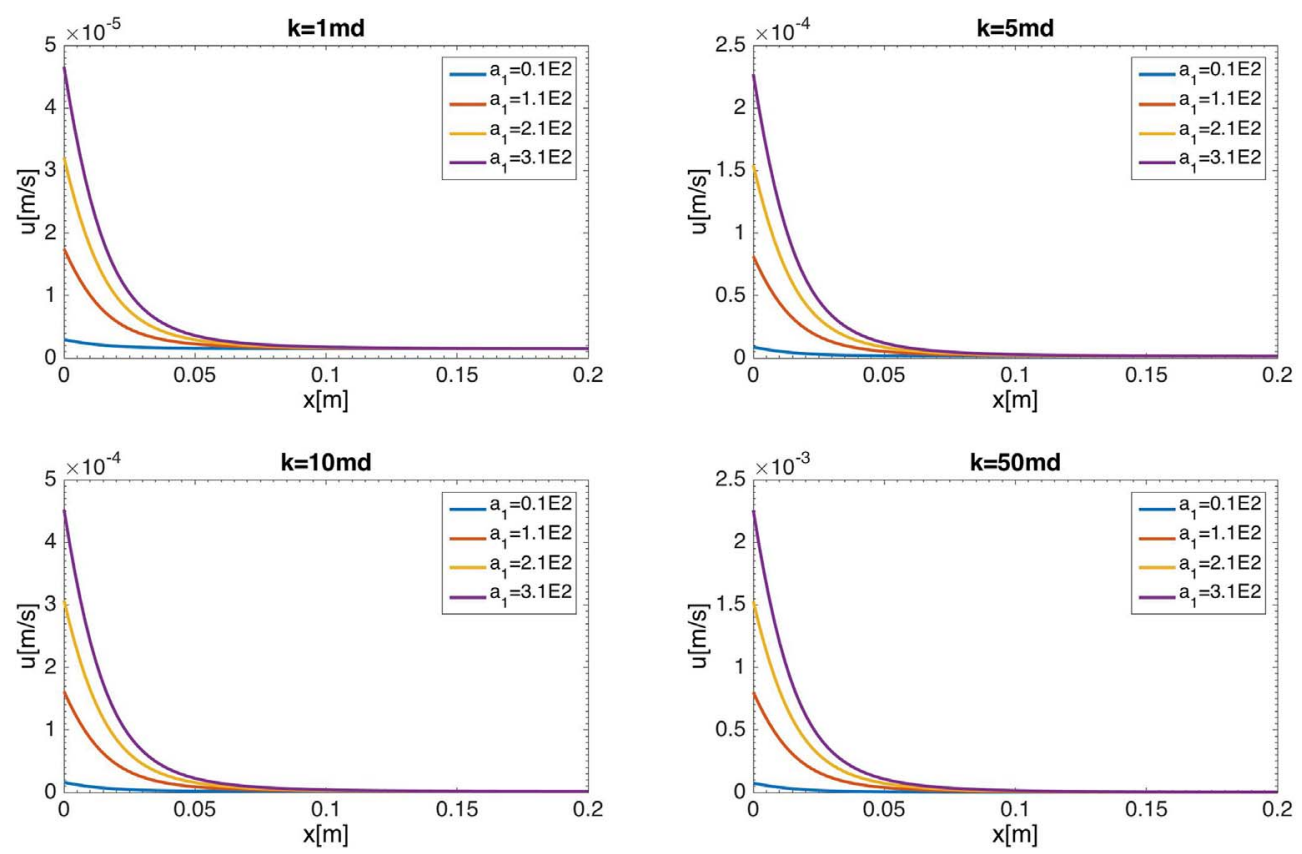

Fig. 2. Effects of the magnetic parameter $a_{1}$ and the permeability $k$ on the velocity profiles along the core length at $t=25[-]$, $B_{r}=1.19[\mathrm{~T}], a=b=0.0254[\mathrm{~m}], L=0.127[\mathrm{~m}], \mu_{0}=4 \times 10^{-7}\left[\mathrm{~T} \mathrm{~m} \mathrm{~A}^{-1}\right], b_{1}=3 \times 10^{-5}\left[\mathrm{~m} \mathrm{~A}^{-1}\right], p_{0}=1 \times 10^{6}[\mathrm{~Pa}], u_{0}=5 \times 10^{-5}$ $\left[\mathrm{m} \mathrm{s}^{-1}\right], \phi=0.3[-], \mu=0.001\left[\mathrm{~kg} \mathrm{~m}^{-1} \mathrm{~s}^{-1}\right], c_{0}=0.1\left[\mathrm{~m}^{3} \mathrm{~m}^{-3}\right], D=1 \times 10^{-6}\left[\mathrm{~m}^{2} \mathrm{~s}^{-1}\right], f=0.0[-], \rho_{r}=2580\left[\mathrm{~kg} \mathrm{~m} \mathrm{~m}^{-3}\right], B=1.016$ $\left[\mathrm{m}^{3} \mathrm{~m}^{-3}\right], d=0.01[-]$ and $c_{\mathrm{ad}, \max }=0.001\left[\mathrm{~m}^{3} \mathrm{~m}^{-3}\right] .\left(1[\mathrm{md}]=0.9869 \times 10^{-15}\left[\mathrm{~m}^{2}\right]\right)$.

parameter $a_{1}$ and permeability on the concentration profiles against the core length under the same above conditions are plotted in Figure 3. This figure indicates that as the magnetization increases the concentration increases. The magnetization has a significant effect on concentration for a big permeability, which is diminished for small values of permeability. Also, the same figure shows the distribution of $u$ and $c$ against the core length, $x[\mathrm{~m}]$. The velocity and concentration are smaller as they get farther away from the source of velocity and concentration. In order to see the effect of $a_{1}$ on the pressure profiles we used the same above parameters except $b_{1}=3 \times 10^{-3}$. In Figure 4 the pressure profiles against the core length, $x[\mathrm{~m}]$. It can be seen from this figure that both permeability and magnetization reduces the pressure. In Figure 5 the effects of the diffusion coefficient $D$ and the permeability $k$ on the concentration profiles along the core length are presented at the above stated parameters with $a_{1}=3 \times 10^{2}\left[\mathrm{~A} \mathrm{~m}^{-1}\right]$. It is interesting to notice that for high permeabilities the advection dominates, and the opposite is true for lower permeabilities the diffusion effect takes place.

In order to study the effect of the universal parameter $R_{\phi}$ on the concentration distribution, we discuss the effect of its primary parameters, namely, $d, c_{\text {ad,max }}, f, \phi, \rho_{r}$ and $B$. Figure 6 illustrates the concentration profiles along time and distance for various values of the adsorption parameters $d$ and $c_{\text {ad,max }}$ at $k=0.5$ [md], $D=1 \times 10^{-6}\left[\mathrm{~m}^{2} \mathrm{~s}^{-1}\right]$, $B_{r}=1.19[\mathrm{~T}], \quad a=b=0.0254 \quad[\mathrm{~m}], \quad L=0.127 \quad[\mathrm{~m}]$, $\mu_{0}=4 \times 10^{-7}, \quad a_{1}=1 \times 10^{2} \quad\left[\mathrm{~A} \quad \mathrm{~m}^{-1}\right], \quad b_{1}=3 \times 10^{-5}$ $\left[\mathrm{m} \quad \mathrm{A}^{-1}\right], \quad p_{0}=1 \times 10^{6} \quad[\mathrm{~Pa}], \quad u_{0}=5 \times 10^{-5} \quad\left[\begin{array}{ll}\mathrm{m} & \mathrm{s}^{-1}\end{array}\right]$, $\phi=0.3[-], \mu=0.001\left[\mathrm{~kg} \mathrm{~m} \mathrm{~m}^{-1} \mathrm{~s}^{-1}\right], c_{0}=0.1\left[\mathrm{~m}^{3} \mathrm{~m}^{-3}\right]$, $f=0.0[-], \rho_{r}=2580\left[\mathrm{~kg} \mathrm{~m}^{-3}\right]$ and $B=1.016\left[\mathrm{~m}^{3} \mathrm{~m}^{-3}\right]$. It is clear from this figure that concentration increases with time while both $d$ and $c_{\text {ad,max }}$ reduce the polymer concentration. Thus, as the adsorption rate increases the polymer concentration in the fluid decreases, which is natural. The effects of porosity $\phi$ and the inaccessible pore volume parameter $f$ on the concentration are plotted against time and distance in Figure 7 at $k=1$ [md], $D=1 \times 10^{-6}\left[\mathrm{~m}^{2} \mathrm{~s}^{-1}\right]$, $B_{r}=1.19[\mathrm{~T}], \quad a=b=0.0254 \quad[\mathrm{~m}], \quad L=0.127 \quad[\mathrm{~m}]$, $\mu_{0}=4 \times 10^{-7}\left[\begin{array}{llll}\mathrm{T} & \mathrm{m} & \mathrm{A}^{-1}\end{array}\right], \quad a_{1}=1 \times 10^{2} \quad\left[\begin{array}{ll}\mathrm{A} & \mathrm{m}^{-1}\end{array}\right]$, $b_{1}=3 \times 10^{-5}\left[\mathrm{~m} \mathrm{~A}^{-1}\right], p_{0}=1 \times 10^{6} \quad[\mathrm{~Pa}], u_{0}=5 \times 10^{-5}$

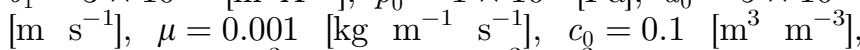
$\rho_{r}=2580\left[\mathrm{~kg} \mathrm{~m}^{-3}\right], B=1.016\left[\mathrm{~m}^{3} \mathrm{~m}^{-3}\right], d=0.01[-]$ and $c_{\text {ad,max }}=0.001\left[\mathrm{~m}^{3} \mathrm{~m}^{-3}\right]$. From this figure one may observe as the porosity increases the polymer concentration decreases. The opposite is true for the effect of the inaccessible pore volume parameter. The concentration profiles along time and distance for various values of the magnetic parameters $B_{r}$ and $b_{1}$ are presented in Figure 8. It is clear that both the magnetic parameters $B_{r}$ and $b_{1}$ enhance the polymer concentration. The pressure and velocity profiles are plotted against the distance in Figure 9 for various values of the magnetic parameters $B_{r}$ and $b_{1}$ at $k=10, D=1 \times 10^{-6}\left[\mathrm{~m}^{2} \mathrm{~s}^{-1}\right], \phi=0.3[-], f=0.0[-]$, $a=b=0.0254 \quad[\mathrm{~m}], \quad L=0.127 \quad[\mathrm{~m}], \quad \mu_{0}=4 \times 10^{-7}$ $\left[\mathrm{T} \quad \mathrm{m} \mathrm{A}^{-1}\right], \quad a_{1}=1 \times 10^{2} \quad\left[\mathrm{~A} \mathrm{~m}^{-1}\right], \quad p_{0}=1 \times 10^{6} \quad[\mathrm{~Pa}]$, $u_{0}=5 \times 10^{-5}\left[\mathrm{~m} \mathrm{~s}^{-1}\right], \mu=0.001\left[\mathrm{~kg} \mathrm{~m}^{-1} \mathrm{~s}^{-1}\right], c_{0}=0.1$ $\left[\begin{array}{ll}\mathrm{m}^{3} & \mathrm{~m}^{-3}\end{array}\right], \quad \rho_{r}=2580 \quad\left[\begin{array}{ll}\mathrm{kg} & \mathrm{m}^{-3}\end{array}\right], \quad B=1.016 \quad\left[\begin{array}{ll}\mathrm{m}^{3} & \mathrm{~m}^{-3}\end{array}\right]$, 

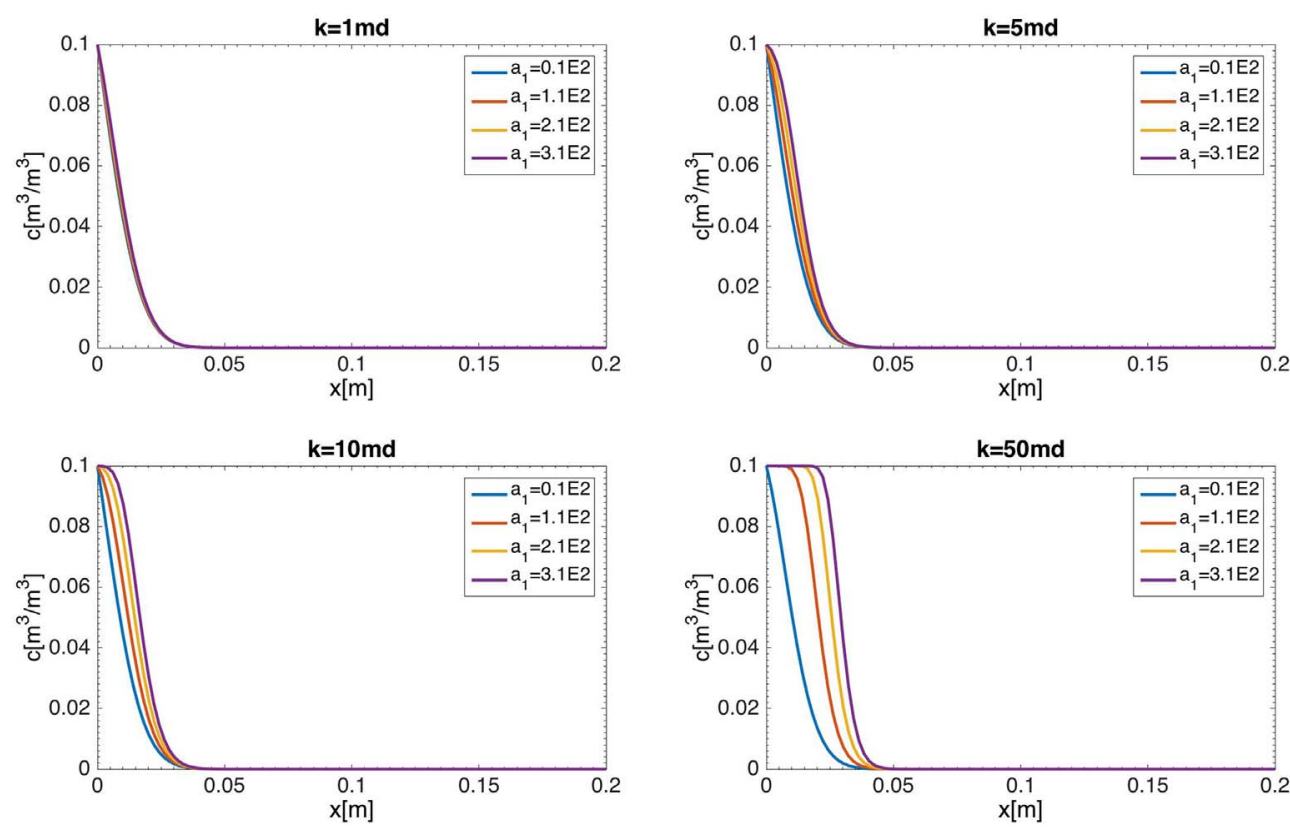

Fig. 3. Effects of the magnetic parameter $a_{1}$ and the permeability $k$ on the concentration profiles along the core length at $t=25[-]$, $B_{r}=1.19[\mathrm{~T}], a=b=0.0254[\mathrm{~m}], L=0.127[\mathrm{~m}], \mu_{0}=4 \times 10^{-7}\left[\mathrm{~T} \mathrm{~m} \mathrm{~A}^{-1}\right], b_{1}=3 \times 10^{-5}\left[\mathrm{~m} \mathrm{~A}^{-1}\right], p_{0}=1 \times 10^{6}, u_{0}=5 \times 10^{-5}\left[\mathrm{~m} \mathrm{~s}^{-1}\right]$, $\phi=0.3[-], \mu=0.001\left[\mathrm{~kg} \mathrm{~m} \mathrm{~s}^{-1} \mathrm{~s}^{-1}\right], c_{0}=0.1\left[\mathrm{~m}^{3} \mathrm{~m}^{-3}\right], D=1 \times 10^{-6}\left[\mathrm{~m}^{2} \mathrm{~s}^{-1}\right], f=0.0, \rho_{r}=2580\left[\mathrm{~kg} \mathrm{~m}^{-3}\right], B=1.016\left[\mathrm{~m}^{3} \mathrm{~m}^{-3}\right]$, $d=0.01[-]$ and $c_{\text {ad,max }}=0.001\left[\mathrm{~m}^{3} \mathrm{~m}^{-3}\right] .\left(1[\mathrm{md}]=0.9869 \times 10^{-15}\left[\mathrm{~m}^{2}\right]\right)$.
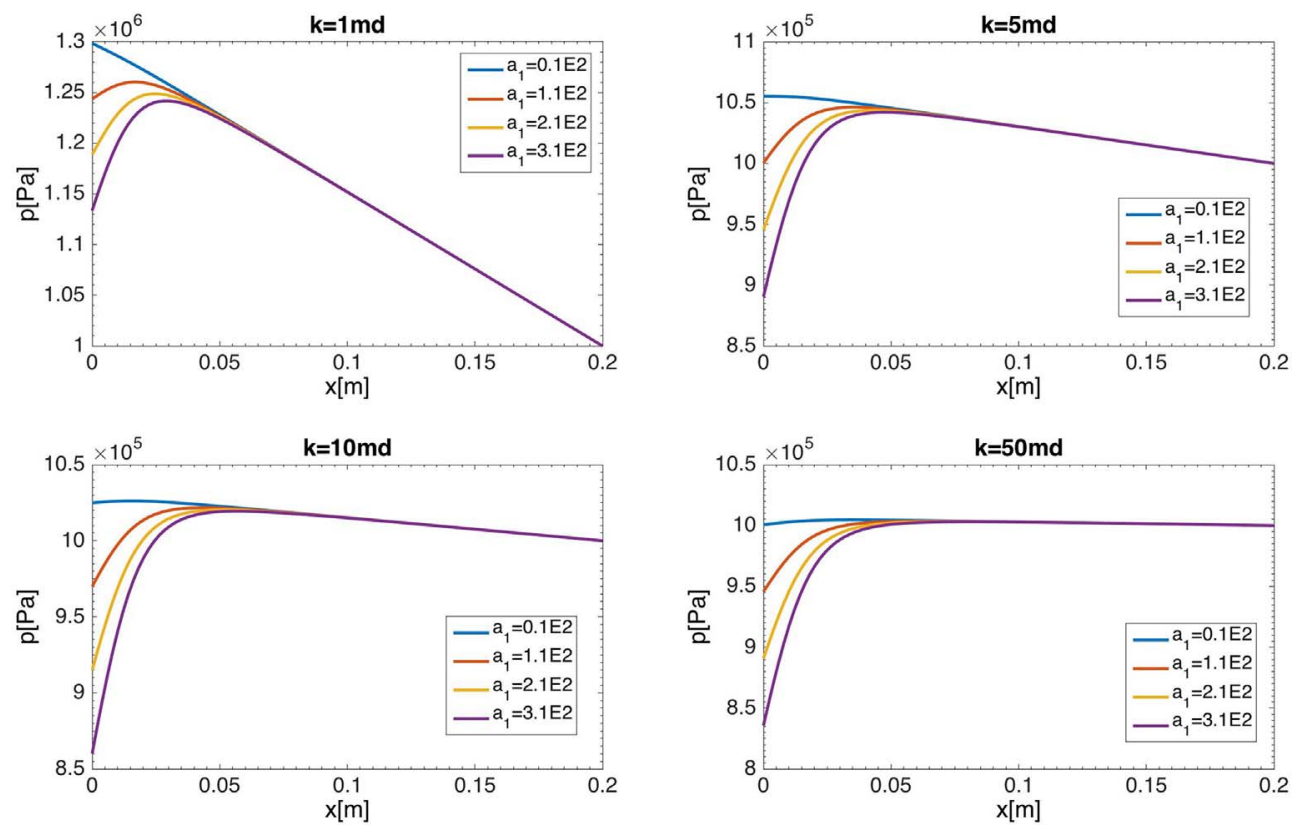

Fig. 4. Effects of the magnetic parameter $a_{1}$ and the permeability $k$ on the pressure profiles along the core length at $t=25[-]$, $B_{r}=1.19[\mathrm{~T}], a=b=0.0254[\mathrm{~m}], L=0.127[\mathrm{~m}], \mu_{0}=4 \times 10^{-7}\left[\mathrm{~T} \mathrm{~m} \mathrm{~A}^{-1}\right], b_{1}=3 \times 10^{-3}\left[\mathrm{~m} \mathrm{~A}^{-1}\right], p_{0}=1 \times 10^{6}[\mathrm{~Pa}], u_{0}=5 \times 10^{-5}$ $\left[\mathrm{m} \mathrm{s}^{-1}\right], \phi=0.3[-], \mu=0.001\left[\mathrm{~kg} \mathrm{~m}^{-1} \mathrm{~s}^{-1}\right], c_{0}=0.1\left[\mathrm{~m}^{3} \mathrm{~m}^{-3}\right], D=1 \times 10^{-6}\left[\mathrm{~m}^{2} \mathrm{~s}^{-1}\right], f=0.0[-], \rho_{r}=2580\left[\mathrm{~kg} \mathrm{~m} \mathrm{~m}^{-3}\right], B=1.016$ $\left[\mathrm{m}^{3} \mathrm{~m}^{-3}\right], d=0.01[-]$ and $c_{\text {ad, } \max }=0.001\left[\mathrm{~m}^{3} \mathrm{~m}^{-3}\right] .\left(1[\mathrm{md}]=0.9869 \times 10^{-15}\left[\mathrm{~m}^{2}\right]\right)$. 

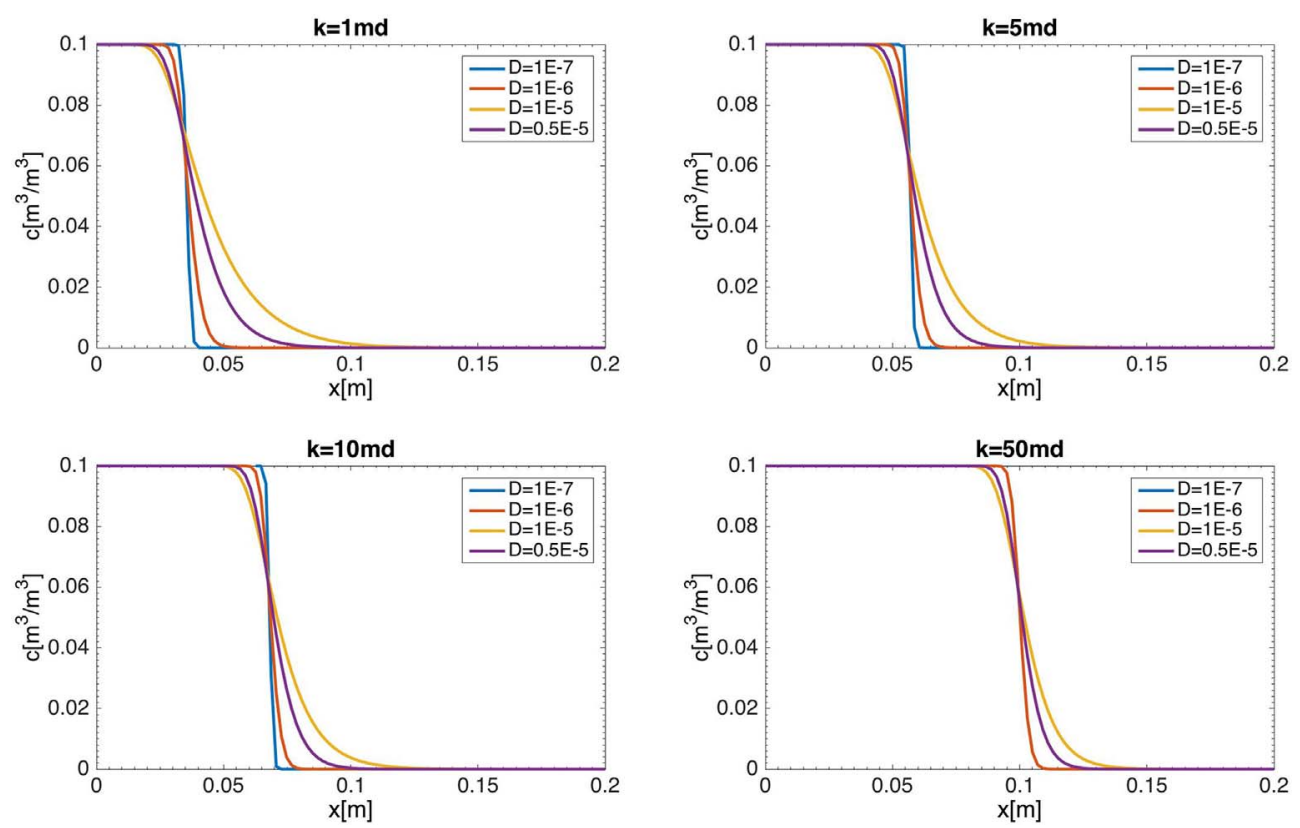

Fig. 5. Effects of the diffusion coefficient $D$ and the permeability $k$ on the concentration profiles along the core length at $t=25[-]$, $B_{r}=1.19[\mathrm{~T}], a=b=0.0254[\mathrm{~m}], L=0.127[\mathrm{~m}], \mu_{0}=4 \times 10^{-7}\left[\mathrm{~T} \mathrm{~m} \mathrm{~A}^{-1}\right], a_{1}=3 \times 10^{2}\left[\mathrm{~A} \mathrm{~m}^{-1}\right], b_{1}=3 \times 10^{-5}\left[\mathrm{~m} \mathrm{~A}^{-1}\right], p_{0}=1 \times 10^{6}$ $[\mathrm{Pa}], u_{0}=5 \times 10^{-5}\left[\mathrm{~m} \mathrm{~s}^{-1}\right], \phi=0.3[-], \mu=0.001\left[\mathrm{~kg} \mathrm{~m}^{-1} \mathrm{~s}^{-1}\right], c_{0}=0.1\left[\mathrm{~m}^{3} \mathrm{~m}^{-3}\right], f=0.0[-], \rho_{r}=2580\left[\mathrm{~kg} \mathrm{~m}^{-3}\right], B=1.016\left[\mathrm{~m}^{3} \mathrm{~m}^{-3}\right]$, $d=0.01$ and $c_{\text {ad,max }}=0.001\left[\mathrm{~m}^{3} \mathrm{~m}^{-3}\right] .\left(1[\mathrm{md}]=0.9869 \times 10^{-15}\left[\mathrm{~m}^{2}\right]\right)$.
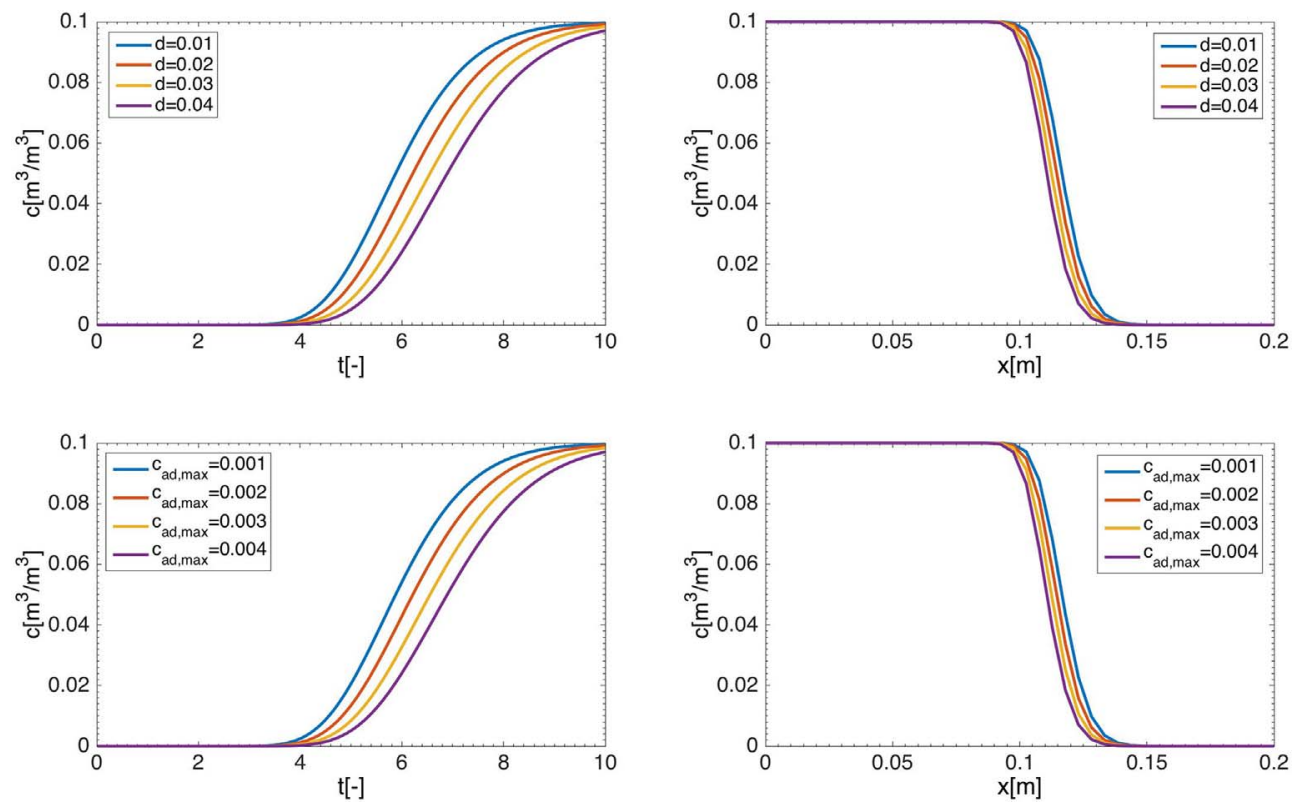

Fig. 6. Concentration profiles along time and distance for various values of the adsorption parameters $d$ and $c_{\text {ad.max }}$ at $k=0.5$, $D=1 \times 10^{-6}\left[\mathrm{~m}^{2} \mathrm{~s}^{-1}\right], B_{r}=1.19[\mathrm{~T}], a=b=0.0254[\mathrm{~m}], L=0.127[\mathrm{~m}], \mu_{0}=4 \times 10^{-7}\left[\mathrm{~T} \mathrm{~m} \mathrm{~A}^{-1}\right], a_{1}=1 \times 10^{2}\left[\mathrm{~A} \mathrm{~m}{ }^{-1}\right], b_{1}=3 \times 10^{-7}$ $\left[\mathrm{m} \mathrm{A}^{-1}\right], p_{0}=1 \times 10^{6}[\mathrm{~Pa}], u_{0}=5 \times 10^{-5}\left[\mathrm{~m} \mathrm{~s}^{-1}\right], \phi=0.3[-], \mu=0.001\left[\mathrm{~kg} \mathrm{~m}^{-1} \mathrm{~s}^{-1}\right], c_{0}=0.1\left[\mathrm{~m}^{3} \mathrm{~m}^{-3}\right], f=0.0[-], \rho_{r}=2580$ $\left[\mathrm{kg} \mathrm{m}^{-3}\right]$ and $B=1.016\left[\mathrm{~m}^{3} \mathrm{~m}^{-3}\right] .\left(1[\mathrm{md}]=0.9869 \times 10^{-15}\left[\mathrm{~m}^{2}\right]\right)$. 

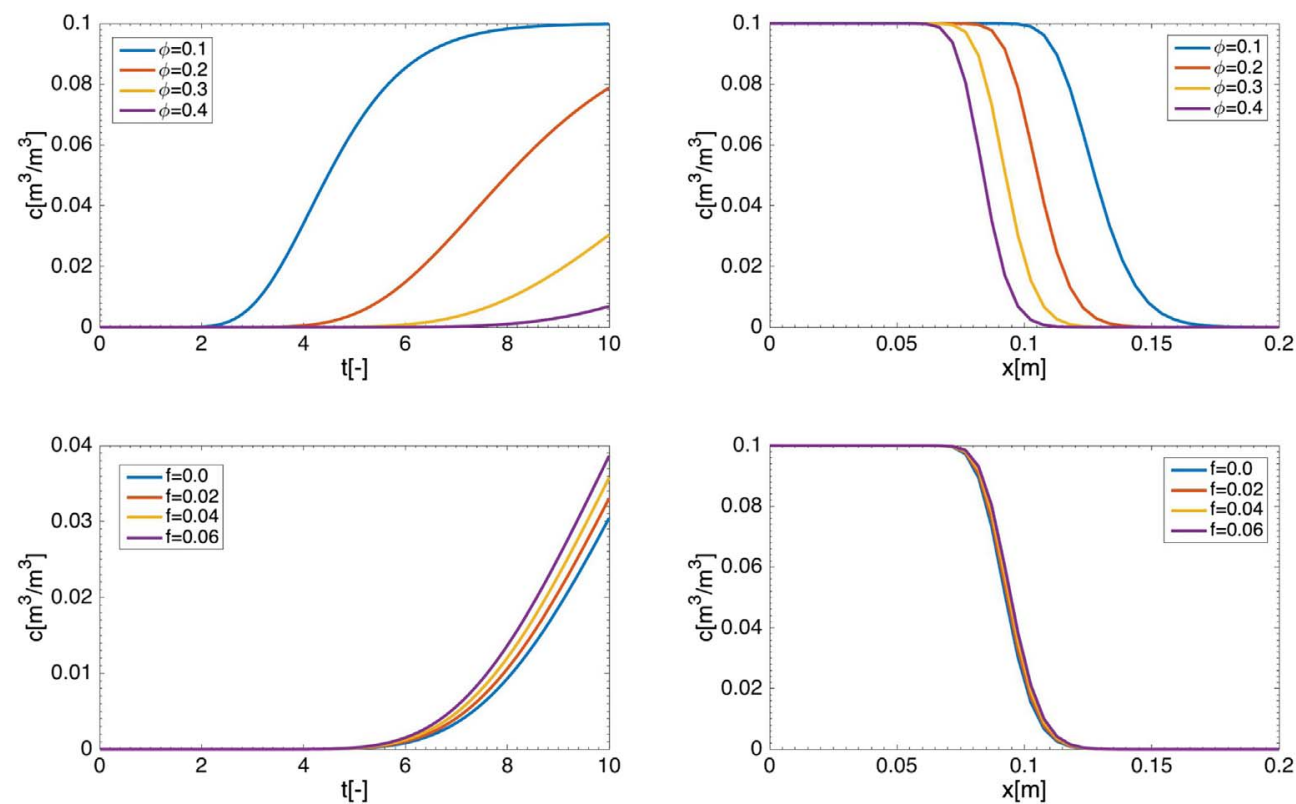

Fig. 7. Concentration profiles along time and distance for various values of porosity $\phi$ and the inaccessible pore volume parameter $f$ at $k=1, D=1 \times 10^{-6}\left[\mathrm{~m}^{2} \mathrm{~s}^{-1}\right], B_{r}=1.19[\mathrm{~T}], a=b=0.0254[\mathrm{~m}], L=0.127[\mathrm{~m}], \mu_{0}=4 \times 10^{-7}\left[\mathrm{~T} \mathrm{~m} \mathrm{~A}^{-1}\right], a_{1}=1 \times 10^{2}\left[\mathrm{~A} \mathrm{~m}{ }^{-1}\right]$, $b_{1}=3 \times 10^{-5}\left[\mathrm{~m} \mathrm{~A}^{-1}\right], p_{0}=1 \times 10^{6}[\mathrm{~Pa}], u_{0}=5 \times 10^{-5}\left[\mathrm{~m} \mathrm{~s}^{-1}\right], \mu=0.001\left[\mathrm{~kg} \mathrm{~m}^{-1} \mathrm{~s}^{-1}\right], c_{0}=0.1\left[\mathrm{~m}^{3} \mathrm{~m}^{-3}\right], \rho_{r}=2580\left[\mathrm{~kg} \mathrm{~m} \mathrm{~m}^{-3}\right]$, $B=1.016\left[\mathrm{~m}^{3} \mathrm{~m}^{-3}\right], d=0.01[-]$ and $c_{\mathrm{ad}, \max }=0.001\left[\mathrm{~m}^{3} \mathrm{~m}^{-3}\right] .\left(1[\mathrm{md}]=0.9869 \times 10^{-15}\left[\mathrm{~m}^{2}\right]\right)$.
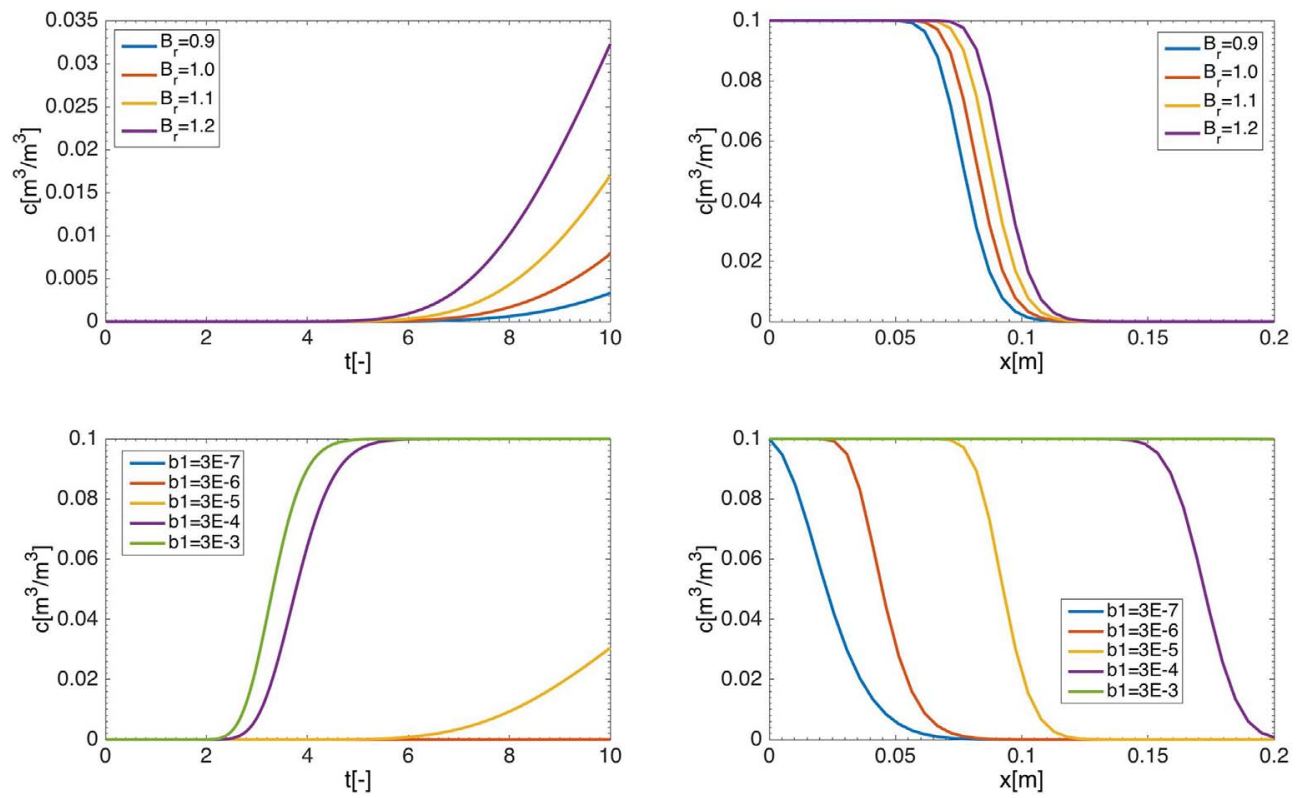

Fig. 8. Concentration profiles along time and distance for various values of the magnetic parameters $B_{r}$ and $b_{1}$ at $k=1$, $D=1 \times 10^{-6}\left[\mathrm{~m}^{2} \mathrm{~s}^{-1}\right], \phi=0.3[-], f=0.0[-], a=b=0.0254[\mathrm{~m}], L=0.127[\mathrm{~m}], \mu_{0}=4 \times 10^{-7}\left[\mathrm{~T} \mathrm{~m} \mathrm{~A}^{-1}\right], a_{1}=1 \times 10^{2}\left[\mathrm{~A} \mathrm{~m}{ }^{-1}\right]$, $p_{0}=1 \times 10^{6}[\mathrm{~Pa}], u_{0}=5 \times 10^{-5}\left[\mathrm{~m} \mathrm{~s}^{-1}\right], \mu=0.001\left[\mathrm{~kg} \mathrm{~m}^{-1} \mathrm{~s}^{-1}\right], c_{0}=0.1\left[\mathrm{~m}^{3} \mathrm{~m}^{-3}\right], \rho_{r}=2580\left[\mathrm{~kg} \mathrm{~m}^{-3}\right], B=1.016\left[\mathrm{~m}^{3} \mathrm{~m}^{-3}\right], d=0.01$ $[-]$ and $c_{\text {ad,max }}=0.001\left[\mathrm{~m}^{3} \mathrm{~m}^{-3}\right] .\left(1[\mathrm{md}]=0.9869 \times 10^{-15}\left[\mathrm{~m}^{2}\right]\right)$. 

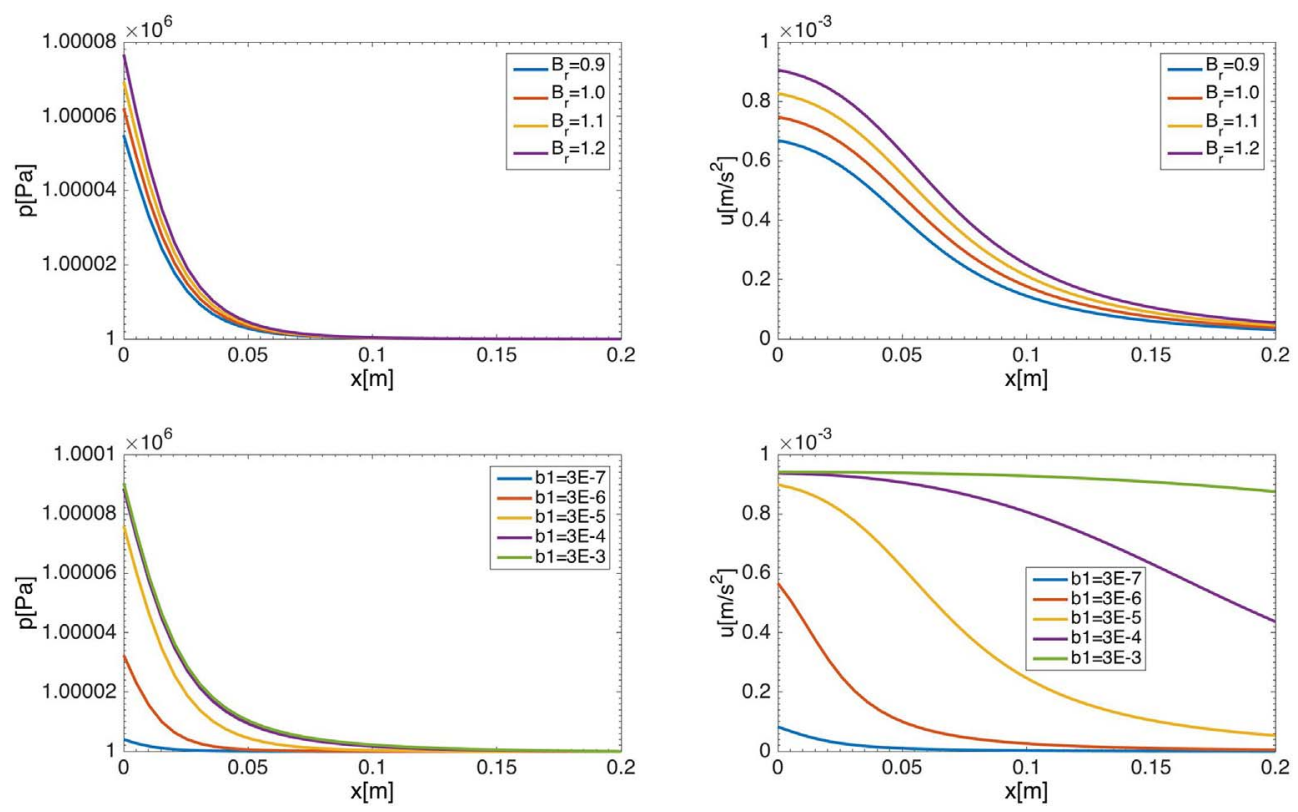

Fig. 9. Pressure and velocity profiles against the distance for various values of the magnetic parameters $B_{r}$ and $b_{1}$ at $k=10$, $D=1 \times 10^{-6}\left[\mathrm{~m}^{2} \mathrm{~s}^{-1}\right], \phi=0.3[-], f=0.0[-], a=b=0.0254[\mathrm{~m}], L=0.127[\mathrm{~m}], \mu_{0}=4 \times 10^{-7}\left[\mathrm{~T} \mathrm{~m} \mathrm{~A} \mathrm{~A}^{-1}\right], a_{1}=1 \times 10^{2}\left[\mathrm{~A} \mathrm{~m}{ }^{-1}\right]$, $p_{0}=1 \times 10^{6}[\mathrm{~Pa}], u_{0}=5 \times 10^{-5}\left[\mathrm{~m} \mathrm{~s}^{-1}\right], \mu=0.001\left[\mathrm{~kg} \mathrm{~m}^{-1} \mathrm{~s}^{-1}\right], c_{0}=0.1\left[\mathrm{~m}^{3} \mathrm{~m}^{-3}\right], \rho_{r}=2580\left[\mathrm{~kg} \mathrm{~m}^{-3}\right], B=1.016\left[\mathrm{~m}^{3} \mathrm{~m}^{-3}\right], d=0.01$ $[-]$ and $c_{\mathrm{ad}, \max }=0.001\left[\mathrm{~m}^{3} \mathrm{~m}^{-3}\right] .\left(1[\mathrm{md}]=0.9869 \times 10^{-15}\left[\mathrm{~m}^{2}\right]\right)$.

$d=0.01[-]$ and $c_{\text {ad,max }}=0.001\left[\mathrm{~m}^{3} \mathrm{~m}^{-3}\right]$. It can be seen from this figure that as the two parameters $B_{r}$ and $b_{1}$ increase the pressure and velocity increase.

\section{Conclusion}

In this work, we developed a model to describe the transport of magnetic polymer in porous media. The analytical solution has been obtained. A sensitivity analysis of the model parameters has been presented. The magnetization has a positive effect on the polymer concentration in particular for high-permeability media, and enhances the flow. One of the interesting results is that for high permeabilities the advection dominates, and for lower permeabilities the diffusion effect takes place. The adsorption parameters are negatively affecting the concentration distribution of the polymer solution. Moreover, it was found that as the porosity increases the concentration increases, while, and as the inaccessible pore volume parameter increases the concentration decreases.

\section{References}

1 Amirian E., Dejam M., Chen Z. (2018) Performance forecasting for polymer flooding in heavy oil reservoirs, Fuel 216, 83-100. doi: 10.1016/j.fuel.2017.11.110.

2 Littmann W. (1988) Polymer flooding, Elsevier, Amsterdam. https://openlibrary.org/books/OL2042456M/Polymer flooding.
3 Lake L.W. (1989) Enhanced Oil Recovery, Prentice-Hall, Upper Saddle River, NJ. https://www.worldcat.org/title/ enhanced-oil-recovery/oclc/18134781.

4 Sorbie K.S. (1991) Polymer-improved oil recovery, Springer Science \& Business Media, Berlin. https://www.springer. com/gp/book/9780216926936.

5 Liang S., Liu Y., Hu S., Shen A., Yu Q., Yan H., Bai M. (2019) Experimental study on the physical performance and flow behavior of decorated polyacrylamide for enhanced oil recovery, Energies 12, 3, 562. doi: 10.3390/en12030562.

6 Li W., Dong Z., Sun J., Schechter D.S. (2014) Polymeralternating-gas simulation: A case study, in: SPE EOR Conference at Oil and Gas West Asia, 31 March-2 April, Muscat, Oman. Society of Petroleum Engineers. doi: 10.2118/169734-MS.

7 Ko S., Lee H., Huh C. (2017) Efficient removal of enhancedoil-recovery polymer from produced water with magnetic nanoparticles and regeneration/reuse of spent particles, SPE Prod. Oper. 32, 3. doi: 10.2118/179576-PA.

8 Duan M., Ma Y., Fang S. (2014) Treatment of wastewater produced from polymer flooding using polyoxyalkylated polyethyleneimine, Sep. Purif. Technol 133, 160-167. doi: 10.1016/j.seppur.2014.06.058.

9 Liu Q., Xu Z., Finch J.A. (2002) A novel two-step silicacoating process for engineering magnetic nanoparticles, Chem. Mater. 10, 12, 3936-3940. doi: 10.1021/cm980370a.

10 Zhao D., Su C., Liu G., Zhu Y., Gu Z. (2019) Performance and autopsy of nanofiltration membranes at an oil-field wastewater desalination plant, Environ. Sci. Pollut. Res. 26, 3, 2681-2690. doi: 10.1007/s11356-018-3797-x.

11 Zhao G., Li J., Gu C., Li L., Sun Y., Dai C. (2018) Dispersed particle gel-strengthened polymer/surfactant as a novel combination flooding system for enhanced oil recovery, 
Energy Fuels 32, 11, 11317-11327. doi: 10.1021/acs. energyfuels.8b02720.

12 Ming L., Vashaee S., Romero-Zeron L., Marica F., Balcom B.J. (2017) A magnetic resonance study of low salinity water-flooding for enhanced oil recovery, Energy Fuels 31, 10, 10802-10811. doi: 10.1021/acs.energyfuels.7b02166.

13 Lyu C., Wang Q., Ning Z., Chen M., Li M., Chen Z., Xia Y. (2018) Investigation on the application of NMR to spontaneous imbibition recovery of tight sandstones: An experimental study, Energies 11, 9, 2359. doi: 10.3390/en11092359.

14 Oldenburg C.M., Borglin S.E., Moridis G.J. (2000) Numerical simulation of ferrofluid flow for subsurface environmental engineering applications, Trans. Porous Med. 38, 319. doi: 10.1023/A:1006611702281.

15 El-Amin M.F., Khalid U., Beroual A. (2018) Magnetic field effect on a ferromagnetic fluid flow and heat transfer in a porous cavity, Energies 11, 11, 3235. doi: 10.3390/en11113235.

16 El-Amin M.F., Brahimi T. (2017) Numerical modeling of magnetic nanoparticles transport in a two-phase flow in porous media, in: SPE-185973-MS, SPE Reservoir Characterisation and Simulation Conference, 8-10 May, Abu Dhabi, UAE. doi: 10.2118/185973-MS.

17 El-Amin M.F., Saad A.M., Sun S., Salama A. (2017) Numerical simulation of magnetic nanoparticles injection into two-phase flow in a porous medium, Procedia Comp. Sci. 2017, 2260-2264. doi: 10.1016/j.procs.2017.05.010.

18 El-Amin M.F., Saad A.M., Salama A., Sun S. (2017) Modeling and analysis of magnetic nanoparticles injection in water-oil two-phase flow in porous media under magnetic field effect, Geofluids 2017, 12. ID 3602593. doi: 10.1155/ $2017 / 3602593$.
19 Kamachi M. (2002) Magnetic polymers, J. Macromol. Sci. Part C: Polym. Rev. 42, 4, 541-561. doi: 10.1081/MC120015990.

20 Ford Versypt A.N., Arendt P.D., Pack D.W., Braatz R.D. (2015) Derivation of an analytical solution to a reactiondiffusion model for autocatalytic degradation and erosion in polymer microspheres, PLoS One 10, 8, e0135506. doi: 10.1371/journal.pone.0135506.

21 Lyu S., Sparer R., Untereker D. (2005) Analytical solutions to mathematical models of the surface and bulk erosion of solid polymers, J Polym. Sci. Part B: Polym. Phys. 43, 4, 383-397. doi: 10.1002/polb.20340.

22 Rosensweig R.E. (1985) Ferrohydrodynamics, Cambridge University Press, Cambridge. https://www.worldcat.org/title/ ferrohydrodynamics/oclc/807640422\&referer=brief_results.

23 Xin X., Yu G., Chen Z., Wu K., Dong X., Zhu Z. (2018) Effect of polymer degradation on polymer flooding in heterogeneous reservoirs, Polymers 10, 8, 857. doi: $10.3390 /$ polym10080857.

24 Bao K., Lie K.A., Moyner O., Liu M. (2017) Fully implicit simulation of polymer flooding with MRST, Comput Geosci 21, 1219. doi: 10.1007/s10596-017-9624-5.

25 Flory P.J. (1953) Principles of polymer chemistry, Cornell University Press, Ithaca, NY. https://www.worldcat.org/ title/principles-of-polymer-chemistry/oclc/542497.

26 Lapidus L., Amundson N.R. (1952) Mathematics of adsorption in beds. VI. The effects of longitudinal diffusion in ion exchange and chromatographie columns, J. Phys. Chem. 56, 984-988. doi: 10.1021/j150500a014. 